\title{
Improving the accuracy: volatility modeling and forecasting using high-frequency data and the variational component
}

\author{
Manish Kumar \\ Department of Management Studies, Indian Institute of Technology Madras (INDLA) \\ manishkumariitm@yahoo.co.in
}

Received September 2009

Accepted February 2010

Abstract: In this study, we predict the daily volatility of the S\&P CNX NIFTY market index of India using the basic 'heterogeneous autoregressive' (HAR) and its variant. In doing so, we estimated several HAR and Log form of HAR models using different regressor. The different regressors were obtained by extracting the jump and continuous component and the threshold jump and continuous component from the realized volatility. We also tried to investigate whether dividing volatility into simple and threshold jumps and continuous variation yields a substantial improvement in volatility forecasting or not. The results provide the evidence that inclusion of realized bipower variance in the HAR models helps in predicting future volatility.

Keywords: realized volatility, forecasting, time series analysis, autoregressive model

\section{Introduction}

Volatility plays an indispensable role in the theoretical development and application of asset and derivative pricing, optimal portfolio choice and the risks associated with holding various financial instruments (Andersen et al., 2003). Moreover, it is one of the key components used in investment decision-making and various trading systems. However, volatility is latent and cannot be observed directly as other variables like prices or volume. So measuring and modelling the volatility is a pre-eminent issue in financial markets (Poon \& Granger, 2003). This task gets complex, as world financial markets get increasingly interconnected and 
interdependent. So both academics and practitioners have emphasised on volatility over the past three decades. Poon and Granger (2003) gave a comprehensive review of the related literature, concentrating on two important questions. Is volatility forecastable? If it is, which method will provide the best forecasts? The authors conclude that financial market volatility is clearly forecastable. However, the debate is on how far ahead one could accurately forecast and to what extent volatility changes could be predicted.

Various statistical and econometrics models are available for forecasting time series volatilities. The simplest one based on historical price is the Random Walk model. The extension of the idea of Random Walk model is the Historical Average method, the simple Moving Average method, the Exponential Smoothing method and the Exponentially Weighted Moving Average (EWMA) method. The Riskmetrics model uses the EWMA method. The second group of models belongs to the regression family. Under which are the Simple Regression, Autoregressive Integrated Moving Average (ARIMA), Autoregressive Fractionally Integrated Moving Average (AFRIMA) and Threshold Autoregressive models (Poon \& Granger, 2003).

A third and more sophisticated group of time series models is the ARCH family, extensively used by many researchers. ARCH (Engle, 1982) and GARCH (Bollerslev, 1986) models have been used by many academicians and practitioners, to estimate volatility. They have helped understand empirical properties such as volatility clustering, leverage effects in volatility and fat-tails of many financial time series.

A popular and fourth group for modelling changing volatility persistence is the Hamilton (1989) type regime switching (RS) model. Afterwards, the base RS model was extended by coupling the GARCH type heteroskedasticity in each state and the probability of switching between states to be time dependent. Moreover, a regime switching ARCH with leverage effect and a bivariate RS model was also developed that produced better forecasts (Hamilton \& Rauli Susmel, 1994; Hamilton \& Gang Lin, 1996).

The fifth group is centered on the stochastic volatility (SV) modelling, in which volatility is subject to a source of innovations that may or may not be related to those that drive returns. Ghysels et al. (1996) in their survey showed the work related to stochastic volatility. 
In addition to the time series volatility forecasting models, option Implied Standard Deviation (ISD) as a volatility forecast is also used. Lamoureux and Lastrapes (1993) and George Vasilellis and Nigel Meade (1996) in their study found implied ISD predicts equity volatility better than forecasts produced from other time series models.

Various methods for estimating volatility of asset returns also exist. These models and estimators, which assume volatility to be constant, are the oldest ones and they estimate the "unconditional volatility". Traditional estimates such as standard deviation, close-to-close volatility, extreme value estimator of Parkinson (1980) and Garman and Klass (1980) are examples of unconditional volatility. However, they do not incorporate time-varying characteristics. Work of Engle (1982) on $\mathrm{ARCH}$ model led to the development of conditional volatility, which incorporates the time-varying characteristics. Afterwards, many variants of ARCH model have been developed (see Poon \& Granger, 2003 and Pandey, 2003).

Robustness of volatility estimates rely severely on the parametric model specification, as well as particular distribution assumptions. An alternative to proxy the volatility is the use of daily squared returns. However, the study by Anderson and Bollerslev (1998) reveals that because of microstructure frictional effects in the dataset, the volatility estimates based on the model-free method can be very noisy. Thus, the estimate based on daily squared returns is not better than the parametric models mentioned before.

Moreover, in a seminal paper, Andersen and Bollerslev (1998) developed a new methodology to estimate the volatility using intraday high frequency returns. They defined this new measure of volatility as Realised Volatility (RV) and proposed to use it as a proxy for the ex-post realisation of the daily volatility. The basic idea of $\mathrm{RV}$ is that a reliable measure of the asset volatility can be proxied by the summation of squared returns over the relevant horizon. Anderson and Bollerslev (1998) found that RV furnishes a less noisy estimate than the squared returns to the latent volatility.

RV's use has been advocated in a number of recent studies (Andersen et al. (2001a, b) and Barndorff- Nielsen and Shephard (2002a, 2002b)). Bollerslev and Zhou (2002) and Fleming et al. (2003) in their study have illustrated the usefulness of this measure in finance. Moreover, Chung et al. (2008) in their study 
states that RV is a convenient method of circumventing certain data complications, while retaining much of the relevant information within the intraday data for measuring, modelling and forecasting volatility levels over both daily and longer horizons.

Since RV is non-latent, it has not only been used to estimate the predictive performance and adequacy of existing forecasting models (Andersen \& Bollerslev, 1998), but also to explore the predictability of RV (Andreou \& Ghysels, 2002, Maheu \& McCurdy, 2002 , Andersen et al., 2003, Martens et al., 2004, Andersen et al., 2005, Koopman et al., 2005).

However, the main disadvantage of earlier studies using pure time series specifications of RV is that they ignored the benefits of model averaging and did not include additional volatility proxies, which may be advantageous in increasing the accuracy of the time series forecasting models.

Barndorff-Nielsen and Shephard $(2004,2006)$ in their research have presented various new measures of volatility and associated estimators. They decomposed the RV into continuous sample path variations and jumps. The authors extended the theory of quadratic variation of semi martingales and provided an asymptotic statistical foundation for this decomposition procedure, under very general conditions. They developed the most popular Realised Power Variation (RPV) and Realised Bipower Variation (RBV). The idea is to examine the role of jumps and continuous component of volatility in volatility forecasting. RPV is built from the sum of powers of the absolute value of high frequency returns, while RBV is defined as the sum of the products of intraday adjacent returns (Barndorff-Nielsen $\&$ Shephard, 2004, 2006).

These estimates motivate a wide range of useful specifications using RV, RPV of several orders, RBV, a jump and an asymmetric term. Moreover, few studies have also been benefited from the concept of model averaging. Corsi (2004) proposed the heterogeneous autoregressive (HAR) model for RV. The HAR-RV model uses independent variables that are past daily RVs averaged over different horizons (typically a day, a week and a month). The idea is to exploit the slow-decay patterns in autocorrelations exhibited in the RV series. Afterwards Corsi et al. (2005), Bollerslev et al. (2005), Andersen et al. (2007a) formulated new variants of HAR-RV models. 
In a recent study, Corsi et al. (2009) introduced the concept of threshold bipower variation, which is based on the joint use of bipower variation and threshold estimation. Empirical analysis (on the S\&P500 index, single stocks and US bond yields) shows that the proposed techniques improve significantly the accuracy of volatility forecasts especially in periods following the occurrence of a jump. In most recent studies (Ghysels et al. (2006), Andersen et al. (2007), and Forsberg \& Ghysels (2007)), it has been shown that taking volatility measure which is immune to jumps-that is, RPV or BPV measures-provides a good regressor for predicting future volatility.

In this study, we use the basic HAR-RV and its variant to empirically investigate the dynamic behaviour of the daily RV of the S\&P CNX Nifty Index of India. This paper contributes to a growing literature that investigates time series models of RV and their forecasting power in a number of ways. The HAR model proposed by Corsi (2004) and logarithmic version (log-HAR) models are popular methodologies, very successful at modelling the long-term behaviour of volatility in a very simple and parsimonious way. Moreover, while exhibiting good out-of-sample forecasting performance, the HAR-RV model has also been found to substantially outperform several other standard models. The first contribution of the study is to examine whether the use of RBV increases the accuracy volatility forecast. In doing so, we construct RV and RBV at a daily frequency using high frequency intraday observations on returns.

Andersen et al. (2007), Forsberg and Ghysels (2007), Giot and Laurent (2007) and Busch et al. (2006) etc have found that jumps have a null impact in determining future volatility. However, a recent study by Corsi et al. (2009) showed that jump component estimated through the concept of threshold bipower variation significantly improves the accuracy of volatility forecasts. Overall, the results are mixed. So the role of jump and continuous component in volatility forecasting models needs to be re-examined. So our research strives to examine whether forecasting power increases by adding repressor's like jumps and continuous component, as estimated by the model of Corsi et al. (2004) and Corsi et al. (2009). Prior studies have mainly compared the predicting power between single models. So our study also wants to examine the forecasting power of the two different HAR models. 
Although there are studies addressing the issue of forecasting financial time series such as stock market index, most of them are about developed financial markets (UK, US and Japan) but not emerging markets. Nowadays, many international investment bankers and brokerage firms have major stakes in overseas markets. Harvey (1995) found emerging market returns are more likely to be influenced by local information than developed markets; in fact, emerging market returns are generally more predictable than developed market returns, and are more volatile as well. Indian stock markets have received relatively little attention until recently. Now there is more interest and research on Indian market data due to the country's rapid growth and potential opportunities for investors. Since the establishment of National Stock Exchange (NSE), the financial markets in the world's second-most populous nation have attracted considerable global investments. It is believed that our investigation using the Indian stock market data would provide a useful assessment of whether the results reported in the earlier studies apply to stock markets in developing nations as well.

The remaining portion of this paper is organized as follows. Section 2, explains the theory of realized volatility, realized power variation and realized bipower variation. The sample period and methodology used for developing and testing the forecasting models are presented in section 3. The experimental results of the study are discussed in section 4 . Section 5 , concludes with a discussion.

\section{Theoretical framework: RV, RBV and jump component extraction}

As discussed in Chung et al. (2008) the variation and jump components are extracted as follows. Suppose that, along day $t$, the logarithmic prices denoted as $\mathrm{P}_{\mathrm{t}}$ of a given asset follow a stochastic-volatility process, as

$$
P_{t}=P_{0}+\mu(t) d t+\sigma(t) d w t+\kappa(t) d q(t), 0 \leq t \leq T
$$

Where $\mu(t)$ is a continuous and locally bounded variation process, $\sigma(t)$ is the stochastic volatility process, $\mathrm{W}(\mathrm{t})$ denotes a standard Brownian motion, $\mathrm{dq}(\mathrm{t})$ is a counting process with $d q(t)=1$ corresponding to a jump at time $t$ and $d q(t)=0$ corresponding to no jump and $k(t)$ is the jump size.

Our interest is to predict the increments in quadratic variation over certain horizons. The increment in quadratic variation from time t to $t+1$ is defined as 


$$
Q V_{t, t+H}=\int_{t}^{t+H} \sigma^{2}(s) d s+\sum_{t<s<t+H} \kappa^{2}(s)
$$

The quadratic variation increments can be decomposed into two distinct components: integrated volatility (continuous) and discrete jumps. BarndorffNielsen and Shephard (2004) define integrated power variation of order $p$ as

$$
\int_{t}^{t+H} \sigma^{p}(s) d s
$$

, where $0<p \leq 2$

Although the volatility measures present in equation (2) are unobservable, they can nevertheless be estimated from the data. Let the discrete daily returns be denoted by

$$
r_{t, t-1}=P_{t}-P_{t-1} \text {, where } \mathrm{t} \text { refers to daily sampling }
$$

The intra-daily return is then

$$
r_{t, j}^{M}=P_{t, j / M}-P_{t,(j-1) / M}
$$

Where $M$ is the number of observations within a trading day.

The daily $\mathrm{RV}$ is calculated by summing the corresponding $M$ intra-daily squared returns as

$$
R V_{t, t+1}^{M}=\sum_{j=1}^{M}\left(r_{t, j}^{M}\right)^{2}
$$

According to the quadratic variation theory, the $R V_{t, t+1}^{M}$ will converge uniformly in probability to the $\mathrm{QV}_{\mathrm{t}+1}$ with $\mathrm{M} \rightarrow \infty$.

We define RPV and BPV (introduced by Barndorff- Nielsen \& Shephard, 2004; 2006) as

$$
\begin{aligned}
& R P V_{t, t+1}^{M}=\sum_{j=1}^{M}\left|r_{t, j}^{M}\right| \\
& B P V_{t, t+1}^{M}(k)=\mu_{1}^{-2} \sum_{j=k+1}^{M}\left|r_{t, j}^{M}\right|\left|r_{t, j-k}^{M}\right|, \mathrm{k} \geq 0
\end{aligned}
$$


Where $\mu_{1}=\sqrt{\frac{2}{\pi}}=E(Z)$ denotes the mean of the absolute value of the standard Gaussian random variable, Z.

It is possible to reveal that for $M \rightarrow \infty$

$$
\begin{aligned}
& \lim _{M \rightarrow \infty} R P V_{t, t+1}^{M} \rightarrow \int_{t}^{t+1} \sigma(s) d s \equiv \sigma_{t, t+1} \\
& \lim _{M \rightarrow \infty} B P V_{t, t+1}^{M} \rightarrow \int_{t}^{t+1} \sigma^{2}(s) d s \equiv \sigma_{t, t+1}^{2}
\end{aligned}
$$

It should be noted that $B P V_{t, t+1}^{M}$ converges to the continuous path component of the quadratic variation and is unaffected by jumps.

Combining the results of equations (2) and (8), the quadratic variation process can be separated into the continuous path and jump path components by:

$$
R V_{t, t+1}^{M}-B P V_{t, t+1}^{M}=\sum_{t<s<t+1} \kappa^{2}(s)
$$

BPV consistently estimates the integrated variance, even in the presence of jumps. Thus, the difference between RV and BPV is the sum of the squared jumps. Using the results developed by Barndorff-Nielsen and Shephard $(2004,2006)$ and Andersen et al. (2007), the significant jumps and the continuous element is defined as

$$
\begin{aligned}
& J_{t, t+1}^{\alpha}=I\left(Z_{t, t+1}>\Phi_{\alpha}\right)\left(R V_{t, t+1}-B P V_{t, t+1}\right)^{+} \\
& C_{t, t+1}^{\alpha}=R V_{t, t+1}-J_{t, t+1}^{\alpha}
\end{aligned}
$$

Where $\mathrm{I}(\bullet)$ denotes the indicator function, and $\mathrm{Zt}, \mathrm{t}+1$ is normally distributed under the null hypothesis of no jumps with a significance level, $a$, and critical value, $\Phi a$, based on $\mathrm{N}(0,1)$ distribution

Similar to Huang and Tauchen (2005), the significance level of the jump test is $a=$ 0.001.Corsi et al. (2009) introduced the concept of threshold multipower variation, essentially a combination of multipower variation (Barndorff-Nielsen \& Shephard, 2006) and the threshold method of Mancini (2009). 
Based on a threshold function $\Theta(M)$, Mancini (2009) provides alternative estimators of squared and fourth power integrated volatility. Threshold RV is defined as

$$
T R V_{t, t+1}^{M}=\sum_{j=1}^{M}\left|r_{t, j}^{M}\right|^{2} I_{\left\{\left|r_{t, j}^{M}\right|^{2} \leq \Theta(M)\right.}
$$

Where the threshold functions have to satisfy

$$
\lim _{M \rightarrow 0} \Theta(M)=0, \lim _{M \rightarrow 0} \frac{M \log \frac{1}{M}}{\Theta(M)}=0
$$

Mancini (2009) also establishes a central limit theorem for TRV. Extending the concept, Corsi et al. (2009) developed the threshold multi power variation and threshold bipower variation. He defines threshold bipower variation as

$$
T B P V_{t, t+1}^{M}=\mu_{1}^{-2} \sum_{j=k+1}^{M}\left|r_{t, j}^{M}\right|\left|r_{t, j-k}^{M}\right| I_{\left\{\left|r_{t, j-k}^{M}\right|^{2} \leq \nu j-k\right\}} I_{\left\{\left|r_{t, j}^{M}\right|^{2} \leq v j\right\}}
$$

Where $v$ is the positive random threshold function.

The jump component is estimated as

$$
T J_{t, t+1}^{\alpha}=I_{\left\{C-T z>\Phi_{\alpha}\right\}}\left(R V_{t, t+1}-T B P V_{t, t+1}\right)^{+}
$$

And the corresponding continuous part as

$$
T C_{t, t+1}^{\alpha}=R V_{t, t+1}-T J_{t, t+1}^{\alpha}
$$

Hence, in this study we employ the concept of RBV and threshold RBV to estimate the jump and continuous component.

\section{Data and models}

We obtained the intraday data on the S\&P CNX Nifty Index for this study from the Bloomberg database. The S\&P CNX Nifty is a value-weighted stock index of NSE, derived from prices of 50 -largest capitalisation stocks. The sample period is from 1 January 2007 to 15 July 2009. 
It is commonly cited in literature (Atchison et al., 1987, Lo \& Mackinlay, 1988, Andersen \& Bollerslev, 1998) that non-synchronous trading induces serial correlation in the returns process that, in turn, would render the cumulative squared returns measure biased. Moreover, the high frequency data are subjected to the market microstructure effects, due to price discreteness and bid-ask bounces. To remove the effect of microstructure noise and biasness, it is a common practice to sum returns over five or 30 minutes (Andersen et al., (2001, 2005), Barndorff-Nielsen \& Shephard, 2004). Hence, in this study, the five-minute returns were constructed using the nearest neighbour to the five-minute tag excluding the overnight returns.

The data is split into two periods. The first period runs from 1 January 2007 to 31 October 2008, used for model estimation and is classified as in-sample; while the second period runs from 1 November 2008 to 15 July 2009, reserved for out-ofsample forecasting and evaluation. Table 1 lists the descriptive statistics of RV levels. These levels include RV, RBV, the continuous element (C) and the jump element $(\mathrm{J})$ and their log-transform. Table 2 shows the descriptive statistics of the threshold bi-power variance, the threshold continuous element (TC) and the threshold jump component (TJ) and their log-transform.

\begin{tabular}{|l|l|l|l|l|}
\hline Series & Mean & $\begin{array}{l}\text { Standard } \\
\text { Deviation }\end{array}$ & Skewness & Kurtosis \\
\hline Panel A & 0.00082 & 0.00149 & 8.1147 & 90.603 \\
\hline RV & 0.00047 & 0.00054 & 4.4027 & 30.274 \\
\hline RBV & 0.00047 & 0.00054 & 4.4048 & 30.267 \\
\hline C & 0.00035 & 0.00130 & 11.860 & 165.52 \\
\hline J & -7.59612 & 0.84104 & 1.0946 & 4.4115 \\
\hline Panel B & -7.96711 & 0.71770 & 0.8016 & 3.9977 \\
\hline Ln (RB) & -7.97595 & 0.72051 & 0.8101 & 3.9957 \\
\hline Ln (C) & 0.00035 & 0.00129 & 11.813 & 164.54 \\
\hline Ln (J)
\end{tabular}

Table 1. "Descriptive statistics of realized volatility levels". Source: Own contribution

Panel A reports the descriptive statistics of the RV and its variants. The mean of RV is .00082. The sample skewness coefficient is positive, meaning that the distribution of RV is skewed to the right. Moreover, the sample kurtosis coefficient is 90.603 , larger than the normal value of 3 implying that the distribution is highly leptokurtic. The results of RBV, the continuous and jump component series are similar to the RV, implying the distribution of these series is also skewed to the right and leptokurtic. Panel $B$ reports the descriptive statistics for the log- 
transformation of RV, RBV, the C and J. Again the skewness and kurtosis are higher than the standard normal. However, the skewness and kurtosis value have reduced in magnitude compared with the original series.

\begin{tabular}{|l|l|l|l|l|}
\hline Series & Mean & $\begin{array}{l}\text { Standard } \\
\text { Deviation }\end{array}$ & Skewness & Kurtosis \\
\hline Panel A & \multicolumn{2}{l|}{} \\
\hline RV & \multicolumn{2}{|l|}{} \\
\hline TRBV & 0.00082 & 0.00149 & 8.1147 & 90.603 \\
\hline TC & 0.00038 & 0.00045 & 5.3142 & 46.220 \\
\hline TJ Panel B & 0.00044 & 0.00137 & 10.511 & 136.11 \\
\hline Ln (TRV) & 0.00038 & 0.00045 & 5.3271 & 46.346 \\
\hline Ln (TRBV) & -8.19814 & 0.74471 & 0.6092 & 3.8141 \\
\hline Ln (TC) & -8.20383 & 0.74450 & 0.6243 & 3.8315 \\
\hline Ln (TJ) & 0.00044 & 0.00136 & 10.461 & 135.09 \\
\hline
\end{tabular}

Table 2. "Descriptive statistics of threshold realized Volatility levels". Source: Own contribution

Panel A reports the descriptive statistics of the threshold RV and its variants. The values of threshold RBV, the threshold continuous and threshold jump component series are similar to the RV, implying the distribution of these series is also skewed to the right and leptokurtic. Panel B reports the descriptive statistics for the logtransform of the threshold RBV, the threshold continuous and threshold jump component. The values of skewness and kurtosis are higher than the standard normal. However, the skewness and kurtosis value have reduced in magnitude compared with the original series

\subsection{Modelling RV-HAR model}

The HAR model developed by Corsi (2004) provided empirical evidence that it is able to reproduce the observed hyperbolic decay of the sample autocorrelations of $R V$. The result of the forecasting performance of HAR model suggests that it is strong and similar to that of ARFIMA models. Corsi (2004) suggests that since the performance of ARFIMA and HAR models are similar and given the straightforward estimation of the latter, the HAR model may be preferable in practice. Moreover, Corsi (2004) also suggests that the HAR model can capture the long-term property of RV in a very simple and parsimonious way. Hence, in this study, we have used HAR model to forecast the RV. 
HAR-RV model of Corsi (2004), including the daily, weekly and monthly RV components, is given by

$$
H A R-V-R V_{t}=\alpha_{0}+\alpha_{d} V_{t-1}+\alpha_{w} V_{t-5: t-1}+\alpha_{m} V_{t-20: t-1}+\varepsilon_{t}
$$

Where $V_{t-h: t}=\frac{1}{h+1}\left(V_{t-h-1}+V_{t-h}+V_{t}\right)$ and $\mathrm{V}=\mathrm{RV}, \mathrm{RBV}$ and TRBV

We follow the HAR-RV model introduced by Corsi (2004) and use different repressors such as RV, BPV and TRBV for predicting RV.

In addition to the HAR-RV model, we also use the following model suggested by Chung et al. (2008).

$$
H A R-C J-R V_{t}=\beta_{0}+\beta_{c d} C_{t-1}+\beta_{c w} C_{t-5: t-1}+\beta_{c m} C_{t-20: t-1}+\beta_{j d} J_{t-1}+\beta_{j w} J_{t-5: t-1}+\beta_{j m} J_{t-20: t-1}+\varepsilon_{t}
$$

Where $\mathrm{C}_{\mathrm{t}-\mathrm{h}}$ and $\mathrm{J}_{\mathrm{t}-\mathrm{h}}$ are the continuous and jump component respectively.

We use the continuous and jump component elements of RV, as separated by the jump test of Barndorff- Nielsen and Shephard (2006).

We modify the HAR-CJ-RV model of Chung et al. (2008) using the continuous and jump component of RV as separated by the jump test of Corsi et al. (2009) using threshold RBV measure.

$$
\begin{aligned}
& H A R-T C J-R V_{t}=\beta_{0}+\beta_{c d} T C_{t-1}+\beta_{c w} T C_{t-5: t-1}+\beta_{c m} T C_{t-20: t-1}+\beta_{j d} T J_{t-1}+ \\
& \beta_{j w} T J_{t-5: t-1}+\beta_{j m} T J_{t-20: t-1}+\varepsilon_{t}
\end{aligned}
$$

Where $\mathrm{TC}_{\mathrm{t}-\mathrm{h}}$ and $\mathrm{TJ} \mathrm{t}-\mathrm{h}$ are the continuous and jump component respectively.

As suggested by Andersen et al. (2007) and Forsberg and Ghysels (2007) and Chung et al. (2008), we also model RV using log-transform. The logarithmic forms of the above equations are as follows:

$$
H A R-V-\log R V_{t}=\alpha_{0}+\alpha_{d} \log V_{t-1}+\alpha_{w} \log V_{t-5: t-1}+\alpha_{m} \log V_{t-20: t-1}+\varepsilon_{t}
$$

Where $\mathrm{V}=\mathrm{RV}, \mathrm{RBV}$ and TRBV 


$$
\begin{aligned}
& H A R-C J-\log R V_{t}=\beta_{0}+\beta_{c d} \log C_{t-1}+\beta_{c w} \log C_{t-5: t-1}+\beta_{c m} \log C_{t-20: t-1}+ \\
& \beta_{j d} \operatorname{LogJ}_{t-1}+\beta_{j w} \operatorname{LogJ}_{t-5: t-1}+\beta_{j m} \operatorname{LogJ}_{t-20: t-1}+\varepsilon_{t}
\end{aligned}
$$

Where $\mathrm{C}_{\mathrm{t}-\mathrm{h}}$ and $\mathrm{J} \mathrm{t} \mathrm{h}$ are the continuous and jump components, respectively, as separated by the jump test of Barndorff-Nielsen and Shephard (2006)

$$
\begin{aligned}
& H A R-T C J-R V_{t}=\beta_{0}+\beta_{c d} \log T C_{t-1}+\beta_{c w} \log T C_{t-5: t-1}+\beta_{c m} \operatorname{LogTC}_{t-20: t-1}+ \\
& \beta_{j d} \operatorname{LogTJ}_{t-1}+\beta_{j w} \operatorname{LogTJ}_{t-5: t-1}+\beta_{j m} \operatorname{LogTJ}_{t-20: t-1}+\varepsilon_{t}
\end{aligned}
$$

Where $\mathrm{TC}_{\mathrm{t}-\mathrm{h}}$ and $\mathrm{TJ} \mathrm{t}-\mathrm{h}$ are continuous and jump components, respectively, as separated by the jump test of Corsi et al. (2009)

\subsection{Measure of performance}

Following Forsberg and Ghysels (2007) and Chung et al. (2008) the prediction performance of the various models in this study is evaluated by considering mean square error (MSE), mean absolute error (MAE) and mean absolute percentage error (MAPE). However, Andersen et al. (2007) in their study compared the results of the different models using only adjusted $R^{2}$. Forsberg and Ghysels (2007) suggested that, when transformed variable (such as log or square root) are used as dependent variable, adjusted $\mathrm{R}^{2}$ can not be used to compare different models. Hence, it is necessary to recover the transformed variable in its original form using suitable measure. Thus, after recovering the dependent variable to its original form, we have compared the in-sample and out-of-sample of different models using MSE, MAE and MAPE.

\section{Empirical results}

\subsection{In-sample results}

All the daily forecasting models are estimated using in-sample data which runs from $1^{\text {st }}$ January 2007-31 $1^{\text {st }}$ October 2008. The results of the estimation of HAR and the transformed HAR i.e. LOG HAR model are presented in the Table 3 with the results of the HAR models being presented in Panel A, and the results of LOG-HAR model being presented in Panel $\mathrm{B}$. 


\begin{tabular}{|c|c|c|c|c|c|}
\hline \multicolumn{6}{|c|}{ Panel A: HAR Models } \\
\hline & $\begin{array}{l}\text { HAR-RV } \\
\text { Equation } 19\end{array}$ & $\begin{array}{l}\text { HAR-RBV } \\
\text { Equation } 19\end{array}$ & $\begin{array}{l}\text { HAR-TRBV } \\
\text { Equation } 19 \\
\end{array}$ & $\begin{array}{l}\text { HAR-CJ-RBV } \\
\text { Equation } 20\end{array}$ & $\begin{array}{l}\text { HAR-TCJ-RBV } \\
\text { Equation } 21 \\
\end{array}$ \\
\hline$\alpha_{0}$ & 0.00018 & 0.00020 & $0.00024 * *$ & & \\
\hline$\alpha_{d}$ & $0.34510 * * *$ & $0.75607 * * *$ & $1.04616 * * *$ & & \\
\hline$\alpha_{w}$ & $0.31534 *$ & $1.06918 * * *$ & $1.38737 * * *$ & & \\
\hline$\alpha_{m}$ & 0.13785 & $-0.54013 * *$ & $-0.90073 * * *$ & & \\
\hline$\beta_{0}$ & & & & $0.00023^{*}$ & $0.00024 * * *$ \\
\hline$\beta_{c d}$ & & & & -0.21855 & -0.07841 \\
\hline$\beta_{c w}$ & & & & $0.77883^{*} * *$ & $1.08498 * * *$ \\
\hline$\beta_{c m}$ & & & & -0.34119 & 0.27131 \\
\hline$\beta_{j d}$ & & & & $1.54556 * * *$ & $1.32193 * * *$ \\
\hline$\beta_{j w}$ & & & & 0.38930 & -0.41835 \\
\hline$\beta_{j m}$ & & & & $-0.98928 *$ & -0.61641 \\
\hline ADJ $\mathbf{R 2}$ & 0.34699 & 0.46150 & 0.51371 & 0.46660 & 0.61406 \\
\hline MAPE & 0.86091 & 0.53829 & 0.76599 & 0.51359 & 0.82446 \\
\hline MAE & 0.00056 & 0.00045 & 0.00050 & 0.00048 & 0.00051 \\
\hline MSE & $2.23 \mathrm{E}-06$ & $2.15 \mathrm{E}-06$ & $1.99 \mathrm{E}-06$ & $2.02 \mathrm{E}-06$ & $1.97 \mathrm{E}-06$ \\
\hline \multicolumn{6}{|c|}{ Panel B: LOG HAR Models } \\
\hline & $\begin{array}{l}\text { HAR-RV } \\
\text { Equation } 22\end{array}$ & $\begin{array}{l}\text { HAR-RBV } \\
\text { Equation } 22\end{array}$ & $\begin{array}{l}\text { HAR-TRBV } \\
\text { Equation } 22\end{array}$ & $\begin{array}{l}\text { HAR-CJ -RBV } \\
\text { Equation } 23\end{array}$ & $\begin{array}{l}\text { HAR-TCJ-RBV } \\
\text { Equation } 24\end{array}$ \\
\hline$\alpha_{0}$ & $-1.0724 *$ & -0.7589 & -0.8005 & & \\
\hline$\alpha_{d}$ & $0.3346 * * *$ & $0.4806 * * *$ & $0.4929 * * *$ & & \\
\hline$\alpha_{w}$ & $0.4081 * * *$ & $0.6973 * * *$ & $0.7681 * * *$ & & \\
\hline$\alpha_{m}$ & 0.1276 & $-0.3231 * *$ & $-0.4385 * * *$ & & \\
\hline$\beta_{0}$ & & & & -0.2654 & -0.5434 \\
\hline$\beta_{c d}$ & & & & $-171.11 *$ & -55.163 \\
\hline$\beta_{c w}$ & & & & $0.5418 * * *$ & $0.5241 * * *$ \\
\hline$\beta_{c m}$ & & & & 0.0168 & $0.1488 * *$ \\
\hline$\beta_{j d}$ & & & & $0.7524 * *$ & $0.6692 * * *$ \\
\hline$\beta_{j w}$ & & & & 0.0114 & -0.1844 \\
\hline$\beta_{j m}$ & & & & $-0.4171 * * *$ & $-0.3127 *$ \\
\hline ADJ $R 2$ & 0.52986 & 0.61293 & 0.62375 & 0.50740 & 0.62813 \\
\hline MAPE & 0.55778 & 0.85463 & 0.53834 & 0.85156 & 0.56993 \\
\hline MAE & 0.00045 & 0.00054 & 0.00046 & 0.00052 & 0.00046 \\
\hline MSE & $1.98 \mathrm{E}-06$ & $2.17 \mathrm{E}-06$ & $2.01 \mathrm{E}-06$ & $2.01 \mathrm{E}-06$ & $1.99 \mathrm{E}-06$ \\
\hline
\end{tabular}

Table 3: "In-sample Prediction Accuracy". Source: Own contribution 
The results for the coefficient of the HAR (equation 19-21) and LOG-HAR (equation 22-24) model in Panel A and B suggests, RBV and the TRBV is the best regressor in the HAR and transformed Log HAR specification (equation 19 and 22). The daily, weekly and monthly coefficients of RBV and TRBV are significant at $1 \%$ level. This confirms the existence of highly persistent volatility dependence.

The coefficient (daily, weekly and monthly) of jump and continuous component as extracted using by Barndorff-Nielsen and Shephard (2004, 2006) and Corsi et al. (2009) are not significant in many cases (equation 20,21, 23 and 24). The results also show that only the daily jump coefficient is positive and significant at $1 \%$ level. This suggests that the daily jump may play a role in future volatility forecast.

The results presented in Panel $A$ and $B$ also gives the adjusted $R^{2}$ values for the HAR and the LOG HAR models. It is noticed that the adjusted $R^{2}$ is higher for the LOG HAR model which also confirms the findings of (Andersen et al. (2007) and Forsberg and Ghysels (2007) and Chung et al. (2008).

In the earlier subsection, we discussed that adjusted $\mathrm{R}^{2}$ cannot be used to compare different models. Hence, we resort to the various error measures to compare the in-sample performance of the RV forecasting model. The study use three error measure namely, MAE, MAPE and MSE to compare various models.

A glance at the values of these performance measures suggests that no model emerges as winner in the in-sample data. The forecasting accuracy statistics provide very inconclusive results. The MSE measure suggests that an equation 19 (HAR-TRBV) models is the best, while the two other performance measure i.e. MAE and MAPE suggests that the HAR-RV (equation 19) and HAR-CJ-RBV (equation 20) are the best.

Since, the MAE is a linear score which means that all the individual differences are weighted equally in the average. The MAPE treats forecast errors above the actual observation differently from those below this value. The MSE is a quadratic scoring rule which measures the average magnitude of the error. Since the errors are squared before they are averaged, the MSE gives a relatively high weight to large errors. This means the MSE is most useful when large errors are particularly undesirable. Patton (2006) also in his work has shown that the MSE loss function is robust with regards to the volatility proxy used. Hence, the study will place more 
emphasis on MSE rather than MAE and MAPE. Thus, from an MSE perspective, the HAR-TRBV model is found to provide the best predictions in the in-sample period. The HAR-TRBV model exploits the use of threshold realized bipower variation et al. (Corsi (2009)) to develop the HAR model.

\subsection{Out-of-sample results}

In order to compare the true performance of the forecasting models, it is necessary to evaluate them on previously unseen data. This situation is likely to be the closest to a true forecasting. To achieve this, all models were maintained with an identical out-of-sample period allowing a direct comparison of their forecasting accuracy. The predictive performance of the five models is summarized in Table 4.

\begin{tabular}{|c|c|c|c|c|c|}
\hline \multicolumn{6}{|c|}{ Panel A: HAR Model } \\
\hline & $\begin{array}{c}\text { HAR-RV } \\
\text { Equation } 19\end{array}$ & $\begin{array}{c}\text { HAR-RBV } \\
\text { Equation } 19\end{array}$ & $\begin{array}{l}\text { HAR-TRBV } \\
\text { Equation } 19\end{array}$ & $\begin{array}{l}\text { HAR-CJ-RBV } \\
\text { Equation } 20\end{array}$ & $\begin{array}{c}\text { HAR-TCJ-RBV } \\
\text { Equation } 21\end{array}$ \\
\hline MAPE & 0.92107 & 0.54698 & 0.85209 & 0.55539 & 0.98982 \\
\hline MAE & 0.00057 & 0.00044 & 0.00052 & 0.00044 & 0.00056 \\
\hline MSE & $4.39 \mathrm{E}-06$ & $3.92 \mathrm{E}-06$ & $3.98 \mathrm{E}-06$ & $4.42 \mathrm{E}-06$ & $4.10 \mathrm{E}-06$ \\
\hline \multicolumn{6}{|c|}{ Panel B: LOG HAR Models } \\
\hline & $\begin{array}{c}\text { HAR-RV } \\
\text { Equation } 22\end{array}$ & $\begin{array}{c}\text { HAR-RBV } \\
\text { Equation } 22\end{array}$ & $\begin{array}{l}\text { HAR-TRBV } \\
\text { Equation } 22\end{array}$ & $\begin{array}{l}\text { HAR-CJ-RBV } \\
\text { Equation } 23\end{array}$ & $\begin{array}{c}\text { HAR-TCJ-RBV } \\
\text { Equation } 24\end{array}$ \\
\hline MAPE & 0.67625 & 1.06432 & 0.62164 & 1.08352 & 0.70795 \\
\hline MAE & 0.00048 & 0.00063 & 0.00047 & 0.00061 & 0.00050 \\
\hline MSE & $3.98 \mathrm{E}-06$ & $3.93 \mathrm{E}-06$ & $3.97 \mathrm{E}-06$ & $3.97 \mathrm{E}-06$ & $3.99 \mathrm{E}-06$ \\
\hline
\end{tabular}

Table 4: "Out-of-Sample Prediction Accuracy". Source: Own contribution

The forecasting accuracy statistics provide very interesting results. A glance at these values shows the superiority of HAR-RBV i.e. Equation 19 with realized bipower variance as regressor. MAE, MSE and MAPE achieved by the HAR-RBV model are quite low indicating that there is a smaller deviation between the actual and predicted. Ghysels et al. (2006) and Forsberg and Ghysels (2007) in their study concluded that the choice of regressor is clearly more important than either the model or the weighting scheme selected for use. The results provided by the HAR-RBV models suggest that realized bipower variance has contributed more in terms of capturing the fluctuations in future volatility.

The results of our study suggests that HAR models involving RBV are invariant to jumps (Barndorff-Nielsen and Shephard $(2004,2006)$ ) and threshold jumps (Corsi et al. 2009)), which implies that, even with the presence of a jump at time $t$, there is no change in the model in terms of its ability to predict future volatility. Our results are consistent with the results shown in Ghysels et al. (2006), Forsberg and 
Ghysels (2007) and Chung et al. (2008) but contradict the findings of Corsi et al. (2009). Thus, the out-of-sample performance measures clearly indicate that RBV based HAR model is the best model in terms of forecasting future volatility.

\section{Conclusion}

In this study, we investigated the volatility of the daily of S\&P CNX Nifty Index realized volatility. We tried to examine whether dividing volatility into jumps and continuous variation yields a substantial improvement in volatility forecasting or not. In doing so, we estimated several HAR and Log form of HAR models using different regressor. The study contributes to the existing literature by comparing the performance of different HAR models and Log HAR models with regressor extracted from the Barndorff-Nielsen and Shephard $(2004,2006)$ and Corsi (2009) methodology. The experimental results obtained using Nifty data show that RBV is the preferred regressor for future volatility prediction. These results hold good for both the in-sample and out-of-sample data. The findings of our study are consistent with the results of Ghysels et al. (2006) and Forsberg and Ghysels (2007) and Chung et al. (2008) but contradict the results of Corsi et al. (2009).

Traders can develop models using HAR-RBV to forecast the RV and use them for better investment decision making. Policy makers can explore the use of such model in predicting realized volatility and examine the impact on other economic indicators of the country.

The study has used an out-of-sample period from November 2008 to July 2009 to examine the performance of the forecasting model. The global financial meltdown of 2008 has impacted the volatility of the various financial markets across the globe. Thus a logical extension of this study would be to examine the robustness of the HAR-RBV model on different test period. Future research can also be done by including a set of potential macroeconomic input variables model. Moreover, the use of nonlinear models can also enhance the predictability of the forecast. There is also scope to compare the performance of these models for different portfolio of stocks using different trading strategies. 


\section{Acknowledgement}

The author would like to thank Davide Pirino (Dipartimento di Fisica, Universit' a di Pisa), Huimin Chung (National Chiao Tung University), Chin-Sheng Huang and Tseng-Chan Tseng (National Yunlin University of Science and Technology) for sharing their research stuff. The author would like to thank the anonymous reviewers for going through the manuscript patiently and critically and sharing his/her views in improving the article.

\section{References}

Andrew, W. L., \& MacKinlay, A. C. (1988). Stock Market Prices do not Follow Random Walks: Evidence from a Simple Specification Test. Review of Financial Studies, 1(1), 41-66. doi: 10.1093/rfs/1.1.41

Andersen, T. G., Bollerslev, T., \& Meddahi, N. (2005) Correcting the errors: volatility forecast evaluation using high-frequency data and realized volatilities. Econometrica, 73(1), 279-296. doi: 10.1111/j.1468-0262.2005.00572.x

Andersen, T. G., Bollerslev, T., Diebold, F. X., \& Labys, P. (2003). Modeling and forecasting realized volatility. Econometrica, 71(2), 579-625.

doi: $10.1111 / 1468-0262.00418$

Andersen, T. G., Bollerslev, T., \& Diebold, F. X. (2007a). Roughing it up: Including jump components in the measurement, modeling and forecasting of return volatility. Review of Economics and Statistics, 89, 701-720.

doi: 10.1162/rest.89.4.701

Andersen, T. G., Bollerslev, T., \& Dobrev, D. (2007b). No-arbitrage semi-martingale restrictions for continuous time volatility models subject to leverage effects, jumps and iid noise: Theory and testable distributional implications. Journal of Econometrics, 138 (1), 125-180. doi: 10.1016/j.jeconom.2006.05.018

Andersen, T. G., Bollerslev, T., Diebold, F. X., \& Ebens, H. (2001a). The Distribution of Realized Stock Return Volatility. J ournal of Financial Economics, 61, 43-76. doi: 10.1016/S0304-405X(01)00055-1 
Andersen, T. G., Bollerslev, T., Diebold, F. X., \& Labys, P. (2001b). The Distribution of Realized Exchange Rate Volatility. Journal of the American Statistical Association, 96, 42-55. doi: 10.1198/016214501750332965

Andersen, T. G., \& Bollerslev, T. (1998). Answering the skeptics: Yes, standard volatility models do provide accurate forecasts. International Economic Review, 39, 885-905. doi: $10.2307 / 2527343$

Andreou, E. \& Ghysels, E. (2002). Rolling-sample volatility estimators: some new theoretical, simulation, and empirical results. Journal of Business and Economic Statistics, 20(3), 363-76. doi: 10.1198/073500102288618504

Atchison, M. D., Butler, K. C., \& Simonds, R. R. (1987). Nonsynchronous Security Trading and Market Index Autocorrelation. Journal of Finance, 42(1), 111-18. doi: $10.2307 / 2328422$

Barndorff-Nielsen, O.E., \& Shephard, N. (2004). Power and Bi-power Variation with Stochastic Volatility and Jumps. J ournal of Financial Econometrics, 2, 1-37. doi: 10.1093/jifinec/nbh001

Barndorff-Nielsen, O.E., \& Shephard, N. (2002a). Econometric Analysis of Realized Volatility and its Use in Estimating Stochastic Volatility Models. Journal of the Royal Statistical Society, 64: 253-80.

Barndorff-Nielsen, O.E., \& Shephard, N. (2002b). Estimating Quadratic Variation Using Realized Variance. Journal of Applied Econometrics, 17, 457-78. doi: 10.1002/jae.691

Barndorff-Nielsen, O.E., \& Shephard, N. (2006). Econometrics of Testing for Jumps in Financial Economics Using Bi-power Variation. Journal of Financial Econometrics, 4, 1-30. doi:10.1093/jifinec/nbi022

Bates, J. M., \& Granger, C. W. J. (1969). The Combination of Forecasts. Operation Research Quarterly, 20, 451-468. doi: 10.1057/jors.1969.103

Bollerslev, T. \& Zhou. H. (2002). Estimating stochastic volatility diffusion using conditional moments of integrated volatility. Journal of Econometrics, 109(1), 3365. doi: 10.1016/S0304-4076(01)00141-5 
Bollerslev, T. (1986). Generalized autoregressive conditional heteroscedasticity. Journal of Econometrics, 31, 307-327. doi:10.1016/0304-4076(86)90063-1

Bollerslev, T., Kretschmer, U., Pigorsch, C., \& Tauchen, G. (2005). A discrete-time model for daily S\&P 500 returns and realized variations: Jumps and leverage effects. Journal of Econometrics.

Brooks, C. (1998). Predicting stock index volatility: can market volume help? Journal of Forecasting, 17, 59-80.

doi: 10.1002/(SICI) 1099-131X(199801) 17: 1<59: : AID-FOR676>3.0.CO;2-H

Corsi, F. (2004). A Simple Long Memory Model of Realized Volatility. Manuscript.

Corsi, F., Pirinos, D. \& Ren, R. (2009). Threshold Bipower Variation and the Impact of Jumps on Volatility Forecasting. Working paper at Dipartimento di Economia Politica, Università di Siena.

Engle, R. F. (1982). Autoregressive conditional heteroscedasticity with estimator of the variance of United Kingdom inflation. Econometrica, 50(4), 987-1008.

doi: $10.2307 / 1912773$

Fleming, J., Kirby, C., \& Ostdiek, B. (2003). The economic value of volatility timing using'realized volatility. Journal of Financial Economics, 67, 473-509. doi: $10.1016 / 50304-405 \times(02) 00259-3$

Forsberg, L., \& Ghysels, E. (2007). Why Do Absolute Returns Predict Volatility So Well? J ournal of Financial Econometrics, 5, 31-67. doi: 10.1093/jjifinec/nbl010

Garman, M. B. \& Klass, M. J. (1980). On the estimation of Security Price Volatilities from Historical data. Journal of Business, 53, 67-78. doi: 10.1086/296072

Ghysels, E., Sinko, A., \& Valkanov, R. (2007). MIDAS Regressions: Further Results and New Directions. Econometric Reviews, 26, 53-90.

doi: $10.1080 / 07474930600972467$

Ghysels, E., Harvey, A., \& Renault, E. (1996). "Stochastic Volatility" in Handbook of Statistics: Statistical Methods in Finance, 14, G.S. Maddala and C.R. Rao, eds. Amsterdam: Elsevier Science, 119-91. 
Hamilton, J. D., \& Lin, G. (1996). Stock Market Volatility and the Business Cycle. Journal of Applied Econometrics, 11(5), 573-93. doi: 10.1002/(SICI)1099-1255(199609)11:5<573: : AID-JAE413>3.0.CO;2-T

Hamilton, J. D., \& Susmel, R. (1994). Autoregressive Conditional Heteroskedasticity and Changes in Regime. Journal of Econometrics, 64(1-2), 307-33. doi: 10.1016/0304-4076(94)90067-1

Hamilton, J. D. (1989). A New Approach to the Economic Analysis of Nonstationary Time Series and the Business Cycle. Econometrica, 57, 357-84. doi: $10.2307 / 1912559$

Harvey, C. R. (1995). The Risk Exposure of Emerging Equity Markets. World Bank Economic Review, 9, 19-50. doi: 10.1093/wber/9.1.19

Huimin, C., Chin-Sheng, H., \& Tseng-Chan, T. (2008). Modeling and Forecasting of Realized Volatility Based on High- Frequency Data: Evidence from Taiwan, International Research J ournal of Finance and Economics.

Koopman, S. J., Jungbacker, B., \& Hol. E. (2005). Forecasting daily variability of the S\&P 100 stock index using historical, realised and implied volatility measurements. J ournal of Empirical Finance, 12(3), 445-475.

doi: 10.1016/i.jempfin.2004.04.009

Lamoureux, C., \&Lastrapes, W. (1993). Forecasting Stock-Return Variance: toward an Understanding of Stochastic Implied Volatilities. Revue of Financial Studies, 6(2), 293-326. doi: 10.1093/rfs/6.2.293

Maheu, J. M. \& McCurdy, T. H. (2002). Nonlinear Features of Realized FX Volatility. The Review of Economics and Statistics, 84(4), 668-681. doi: $10.1162 / 003465302760556486$

Mancini, C. (2009). Non-parametric threshold estimation for models with stochastic diffusion coefficient and jumps. Scandinavian Journal of Statistics, 36(2), 270296. doi: 10.1111/j.1467-9469.2008.00622.x

Martens, M., van Dijk, D. J. C., \& de Pooter, M. (2004). Modeling and forecasting S\&P 500 volatility: Long memory, structural breaks and nonlinearity. Discussion Paper, Tinbergen Institute 
Pandey, A. (2003). Modeling and Forecasting Volatility in Indian Capital Markets, No 2003-08-03, IIMA Working Papers from Indian Institute of Management Ahmedabad, Research and Publication Department.

Parkinson, M. (1980). The extreme value method for estimating the variance of the rate of return. J ournal of Business, 53, 61-65. doi: 10.1086/296071

Patton, A. (2006). Volatility Forecast Comparison Using Imperfect Volatility Proxies. Manuscript, London School of Economics

Poon, S., \& Granger, C. W. R. (2003). Forecasting Volatility in Financial Markets: A Review. J ournal of Economic Literature, 66, 478-539.

doi: $10.1257 / 002205103765762743$

Reid, D.J. (1968). Combining Three Estimates ff Gross Domestic Product. Economica, 35, 431-444. doi: 10.2307/2552350

Tae Hyup, R. (2007). Forecasting the volatility of stock price index. Expert Systems with Applications, 33 (4), 916-922. doi:10.1016/j.eswa.2006.08.001

Vasilellis, G. A. \& Meade, N. (1996). Forecasting Volatility for Portfolio Selection. Journal of Business and Financial Accounting, 23(1), 125-143.

doi: 10.1111/j.1468-5957.1996.tb00407.x

(C) Journal of Industrial Engineering and Management, 2010 (www.jiem.org)

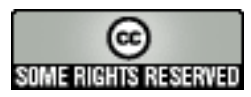

\footnotetext{
Article's contents are provided on a Attribution-Non Commercial 3.0 Creative commons license. Readers are allowed to copy, distribute and communicate article's contents, provided the author's and Journal of Industrial Engineering and Management's names are included. It must not be used for commercial purposes. To see the complete license contents, please visit http://creativecommons.org/licenses/by-nc/3.0/.
} 